\title{
Long-Term Cortisol Concentration in Scalp Hair of Asthmatic Children Using Inhaled Corticosteroids: A Case-Control Study
}

\author{
Maaike P. Smit ${ }^{a} \quad$ Ed H.G. van Leer ${ }^{a} \quad$ Gerard Noppe $^{b} \quad$ Yolanda B. de Rijke $^{c}$ \\ Dieneke Kramer van Driel ${ }^{\mathrm{a}}$ Erica L.T. van den Akker $^{\mathrm{d}}$ \\ ${ }^{a}$ Department of Paediatrics, Groene Hart Hospital, Gouda, The Netherlands; ${ }^{\mathrm{b}}$ Department of Paediatrics and Internal \\ Medicine, Sophia Children's Hospital-Erasmus MC, Rotterdam, The Netherlands; ' Department of Clinical Chemistry, \\ Erasmus MC, Rotterdam, The Netherlands; ' Department of Paediatrics, Sophia Children's Hospital-Erasmus MC, \\ Rotterdam, The Netherlands
}

\section{Keywords}

Cortisol · Hair cortisol concentration · Asthmatic children ·

Corticosteroids

\begin{abstract}
Introduction: Inhaled corticosteroids (ICS) can interfere with the hypothalamic-pituitary-adrenal (HPA) axis and may lead to adrenal insufficiency, resulting in a decrease of cortisol production. Cortisol levels measured in scalp hair provide a marker for long-term cortisol exposure. Data regarding hair cortisol concentration (HCC) in asthmatic children with ICS therapy are scarce. The aim of this study is to compare HCC in asthmatic children under ICS treatment with a healthy control group. Methods: We set up a case-control study measuring the cortisol concentration in scalp hair in asthmatic children $(N=80)$ treated with ICS and healthy controls $(N=252)$ aged 4-18 years. Anthropometric characteristics and hair samples from the posterior vertex were obtained. At least $5 \mathrm{mg}$ of the most proximal $3 \mathrm{~cm}$ of hair was used for each hair sample. HCC was analyzed by liquid chromatography-tandem mass spectrometry. Results: HCC did not significantly differ between asthmatic children using ICS and healthy controls ( $p=0.950)$ after adjustment for age, gender,
\end{abstract}

\begin{tabular}{ll}
\hline KARGER & ( 2017 The Author(s) Karger \\
& Published by S. Karger AG, Basel Open access \\
E-Mail karger@karger.com & This article is licensed under the Creative Commons Attribution- \\
www.karger.com/hrp & $\begin{array}{l}\text { NonCommercial-NoDerivatives 4.0 International License (CC BY- } \\
\text { NC-ND) (http://www.karger.com/Services/OpenAccessLicense). } \\
\text { Usage and distribution for commercial purposes as well as any dis- } \\
\text { tribution of modified material requires written permission. }\end{array}$
\end{tabular}

height, body mass index, and socioeconomic status. No correlation was found between budesonide dosage and HCC levels ( $r=-0.031, p=0.78$ ). Conclusion: There was no evidence of suppression of basal cortisol production, as measured in scalp hair, in asthmatic children using ICS, compared to healthy controls. No conclusions can be drawn on the HPA-axis stress response in these children.

(c) 2017 The Author(s)

Published by S. Karger AG, Basel

\section{Introduction}

Asthma is the most common chronic disease among children worldwide [1]. Inhaled corticosteroids (ICS) are the mainstays of treatment for persistent asthma in children [2]. However, ICS can cause systemic side effects including suppression of the hypothalamic-pituitary-adrenal (HPA) axis with subsequent inability to produce a sufficient amount of cortisol $[3,4]$. Cortisol is a glucocorticoid stress hormone and is important for maintaining blood pressure, blood glucose, and energy levels during times of physiological stress (e.g., surgery or illness) [5]. A deficiency of cortisol can cause physical (e.g., fatigue, malaise, poor weight gain, or poor linear growth) and 
symptoms of mental illness as manifested in Addison's disease and is potentially life-threatening [6-8]. Clinicians are often aware of possible HPA-axis suppression that may occur in cases of long-term or high-dose ICS therapy $[9,10]$. However, recent studies show that HPAaxis suppression may already occur at low-to-moderate ICS doses [11, 12]. In clinical practice, screening for HPAaxis suppression remains challenging since current tests fall short in several aspects. Cortisol measured in serum and saliva provides point estimates of HPA activity and is subject to the circadian rhythm and pulsatile secretion. Urinary measurements of cortisol may span up to $24 \mathrm{~h}$ and provide a rough estimate of cortisol levels over time. However, the collection of urine is often unpractical and unreliable $[13,14]$. A more suitable, relatively new technique is to measure the long-term cortisol concentration in scalp hair $[15,16]$. Previous data have shown that the measurement of hair cortisol successfully reflects endogenous cortisol levels $[17,18]$. Assessment of the hair cortisol concentration (HCC) has been validated, and in children aged 4-18 years, reference ranges have been established [19].

Studies regarding HCC in asthmatic children with ICS therapy are scarce $[20,21]$. The aim of this case-control study was to compare long-term cortisol concentrations in scalp hair of asthmatic children receiving ICS treatment with those of healthy children. Furthermore, we assessed the association between ICS dosage and HCC in asthmatic children.

\section{Methods}

The study was approved by the Medical Ethical Review Board. Written informed consent was obtained from parents and/or guardians and children when aged 12 years and older. Asthmatic children treated with ICS were recruited at the Groene Hart Hospital, a general hospital located in Gouda, The Netherlands, in a period of 3 months (May-July 2014). Asthmatic children were eligible if they were (1) between 4 and 18 years old; (2) on ICS treatment for at least 3 months; (3) had a minimum of 3-cm-long scalp hair on the posterior vertex; (4) did not use systemic corticosteroids, and (5) were not hospitalized in the previous 3 months. Exclusion criteria comprised (1) other chronic diseases (e.g., eczema or anorexia nervosa), and/or (2) medication known to alter glucocorticoid metabolism (e.g., corticosteroids such as prednisone and hydrocortisone therapy). Healthy children were eligible as controls if they were, similar to the case group, (1) between 4 and 18 years old; (2) did not use glucocorticoids at the time of the study or in the previous 3 months, and (3) did not have a chronic disease. Healthy controls were recruited from primary and secondary schools in the Netherlands and among siblings of children attending the pediatric outpatient clinic.

\section{Study Procedure}

Hospital records were used to identify asthmatic children treated with ICS who regularly attended the outpatient clinic. An invitation to take part in the study and information regarding the study was sent to their home address. After informed consent had been retrieved, each child was included during his/her next visitation at the outpatient pediatric department. During this visit, a hair sample was collected, and the weight and height were measured. Body mass index (BMI) was calculated using the formula weight $(\mathrm{kg}) /$ height $\left(\mathrm{m}^{2}\right)$. Dosages, expressed in $\mathrm{m}^{2}$ of the body surface were calculated according to Mostellers' formula [22]. Children were asked if their hair was dyed, bleached, or permed in the past 3 months. Following local health care standards, all children had received information on their asthma condition and training on the use of ICS and the required inhalation technique from a respiratory nurse specialist. The following data were obtained from medical records: demographic data (i.e., gender, age, and socioeconomic status [SES]) and ICS dose as prescribed by the treating physician. Healthy children were invited to take part in the study and received oral and written information. During school visitation, a research nurse collected hair samples and measured the body weight and height. Further demographic information of the healthy controls, data on general health, the use of medication, and hair care were collected through a questionnaire. SES was determined by postal code, in accordance with the study by Knol et al. [23].

\section{Hair Collection and Analysis of Cortisol in Hair}

The hair sample (approx. 100-150 strands) was cut from the posterior vertex of the scalp as close to the scalp as possible. The posterior vertex has proven to display the lowest variance in cortisol concentration, potentially due to a more uniform growth rate [18]. The hair sample was taped to a piece of paper and stored at room temperature. The samples were sent to the laboratory of endocrinology of the Erasmus MC, Rotterdam, The Netherlands. At least $5 \mathrm{mg}$ of the most proximal $3 \mathrm{~cm}$ of hair was weighed for each hair sample. The samples were then processed and analyzed as previously described [24]. The hair samples were cut into $1-\mathrm{cm}$ pieces and washed in LC-MS grade isopropanol for $2 \mathrm{~min}$. After solid phase extraction, hair cortisol was quantified by liquid chromatography-tandem mass spectrometry (LCMS) using a Xevo TQ-S system (Waters Chromatography, Milford, MA, USA).

\section{Statistical Analysis}

Statistical analyses were performed using SPSS 22.0 (IBM Corp., Armonk, NY, USA). Anthropometric standard deviation scores were calculated based on the 1997 Dutch nationwide growth study [25] using Growth Analyser RCT (Growth Analyser B.V., Rotterdam, The Netherlands). The Gaussian distribution of variables was assessed by the Kolmogorov-Smirnov test. Results are presented as the mean (95\% confidence interval [CI]), median (range), and/or numbers (percentages). The ICS usage for each case was converted to a budesonide equivalent in $\mu \mathrm{g} / \mathrm{m}^{2} /$ day, were $100 \mu \mathrm{g}$ beclomethasone extra fine $=200 \mu \mathrm{g}$ budesonide, $100 \mu \mathrm{g}$ beclomethasone $=100 \mu \mathrm{g}$ budesonide, and $100 \mu \mathrm{g}$ fluticasone $=200$ $\mu \mathrm{g}$ budesonide. Univariable analyses were performed using the Student $t$ test or Mann-Whitney $U$ test for continuous variables (subject to the distribution of the respective variables) and the $\chi^{2}$ test for categorical variables. Analyses of covariance was employed with HCC as the dependent variable and the case-control group as 
Table 1. Baseline characteristics of the cases and healthy controls

\begin{tabular}{lccc}
\hline & Cases $(N=80)$ & Healthy controls $(N=252)$ & $p$ value \\
\hline Age, years & $11.0(4.1$ to 17.6$)$ & $11.2(4.3$ to 18.0$)$ & 0.573 \\
Male & $40(50)$ & $126(50)$ & 1.000 \\
Height for age, SDS & $-0.54 \pm 1.3$ & $0.21 \pm 0.9$ & $0.000^{*}$ \\
Weight for age, SDS & $-0.23 \pm 1.2$ & $0.02 \pm 0.8$ & 0.088 \\
BMI, SDS & 0.12 & -0.12 & 0.066 \\
SES score & $0.49(-1.08$ to 1.08$)$ & $0.93(-4.96$ to 2.36$)$ & $0.000^{*}$ \\
Budesonide, $\mu$ g/day & $560(200$ to 1,200$)$ & - & - \\
Budesonide, $\mu \mathrm{g} / \mathrm{m}^{2} /$ day & $512.3(180.7$ to 1394.3$)$ & - & - \\
Hair treatment $($ dyed $),<3$ months & $1(1.3)$ & $5(4.0)$ & 0.352 \\
Hair weight, $\mathrm{mg}$ & $30.9(20.4$ to 36.8$)$ & $30.8(15.4$ to 34.6$)$ & 0.859 \\
HCC, $\mathrm{pg} / \mathrm{mg}$ & $2.06(0.28$ to 20.65$)$ & $2.22(0.28$ to 38.28$)$ & 0.805 \\
\hline
\end{tabular}

Values are mean \pm standard deviation, $n(\%)$, or median (range). SDS, standard deviation score; BMI, body mass index; SES, socioeconomic status; HCC, hair cortisol concentration. SES, cases $n=79$; SES, healthy controls $n=241$; hair treatment (dyed), healthy controls $n=152 .{ }^{*}$ Statistically significant $(p<0.05)$.

the independent variable, while incorporating age, gender, BMI, height, and the SES score as potential confounders. The variables were log-transformed to achieve normality where needed. The Spearman correlation test was used to measure the relationship between the budesonide dose and HCC, with the significance level set at $<0.05$.

\section{Results}

In the 3 months study period, 237 asthmatic patients received an information letter, resulting in the inclusion of 86 cases. In the final statistical analyses, 1 child was excluded due to known inconsistent ICS usage, and 5 children were excluded as a result of missing data on their HCC. All study subjects were outpatient children with mild-to-moderate asthma as defined by the Dutch asthma guideline [26]. The median dose of budesonide in asthmatic children was $512.3 \mu \mathrm{g} / \mathrm{m}^{2} /$ day (range: $180.7-$ 1,394.3) (Table 1). None were hospitalized (intensive care) or attended the emergency department during the study. Both cases and controls did not use steroidcontaining ointments/creams for scalp usage. Asthmatic children were on average of lower height than healthy controls, and of less deprived areas in the Netherlands (i.e., had a lower SES score). Furthermore, the asthmatic children proved to have similar characteristics as our control group (Table 1). In the univariate analysis, the median HCC of asthmatic children (2.06 [range: 0.2820.65]) did not significantly differ from the HCC of healthy controls (2.22 [0.28-38.28], $p=0.805)$. After adjustment for age, gender, height, BMI, and SES score, again no sign of difference between the HCC of asthmatic children and healthy controls was observed $(p=0.950)$. We assessed the correlation between the employed budesonide dosage and HCC and did not find that the amount of received treatment correlated with long-term cortisol concentrations measured in hair $(r=-0.031, p=$ 0.78; Fig. 1).

\section{Discussion}

In this case-control study, we compared the long-term cortisol concentration in scalp hair (HCC) of asthmatic children receiving ICS with HCC in healthy children. Our main finding was that HCC levels in the former group did not significantly differ from that of healthy controls. As hair cortisol is considered an integrated measure of HPA activity over extended periods of time, this study did not find evidence for the suppression of cortisol production in asthmatic children using ICS.

To our knowledge, this study comprises the first effort to compare HCC in a large group of asthmatic children treated with ICS. Two pilot case-control studies similar to the present study have been published [20, 21]. In contrast to our finding, Kamps et al. [20] concluded that HCC in asthmatic children treated with ICS (median 2.0 $\mathrm{pg} / \mathrm{mg}$; 95\% CI 1.4-4.1) was "significantly" lower than HCC in healthy children (4.3 pg/mg; 95\% CI 1.8-5.9, $p$ value not reported). Of note, while markedly different means are reported, the distribution of HCC of both the asthmatic and the control group completely overlap. 


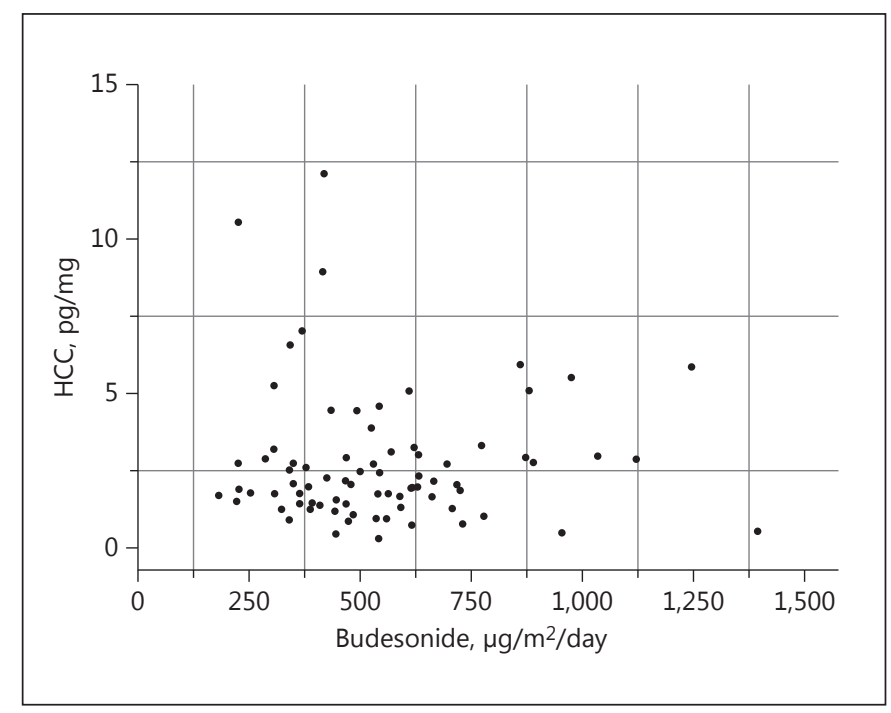

Fig. 1. Correlation between budesonide and hair cortisol concentration (HCC). Spearman correlation $r=-0.031, p=0.78$.

Therefore, the clinical relevance of these results can be questioned. Moreover, due to the small sample size in both their study groups $(n=10)$, confounders were not corrected for. ICS dosage used by the asthmatic children was not reported, which hampers adequate comparison with our finding that budesonide dosage did not correlate with long-term HCCs. A second study by Smy et al. [21] also found that among 18 asthmatic children, HCC was significantly lower during ICS usage compared to a period of no usage (median HCC of $89.8 \mathrm{ng} / \mathrm{g}$ [cases] vs. $198.2 \mathrm{ng} / \mathrm{g}$ in the control group, $p=0.0015$ ). The authors analyzed HCC using 2 measurements of hair strands from the same children, where each child comprised its own control. Enzyme-linked immunosorbent assay (ELISA) was employed for the analysis, a test known to have low sensitivity when measuring in the lower ranges of cortisol concentration. In contrast to our study, children exposed to short courses of systemic corticosteroids or intranasal corticosteroids were not excluded. Moreover, the median age of asthmatic children was markedly younger (4 years, range 1.4-8.8). HCC levels have proven to be high and variable during infancy $[27,28]$. Karlén et al. [27] found that HCC measured in healthy children of 1 and 3 years of age proved to correlate with maternal cortisol levels during pregnancy but after periods of high variability were found to stabilize at older age (5 and 8 years). This could imply that it is difficult to compare our study group with the children in Smy et al. [21]. Finally, as the authors conducted a pilot investigation, it lacked the statistical power to investigate dose-dependent differences in HCC. Further research is needed, in particular as other studies, though having used alternative measurement techniques to scalp hair analysis, also report contradicting findings $[6,12,29]$.

Several studies identified HPA-axis suppression during high ICS dosage in asthmatic children [30,31], while others found an association between HPA suppression and lower ICS dosage $[12,32]$ or no association between ICS dosage and cortisol [33-36]. Despite these inconsistencies, international guidelines have formulated a recommendation on when to measure cortisol during ICS therapy. In a recent guideline, ICS dosing categories in children $>12$ years are defined as low when $\leq 250 \mu \mathrm{g} /$ day fluticasone propionate or equivalent is provided; medium when a child receives $251-500 \mu \mathrm{g} /$ day, and high at levels of $>500 \mu \mathrm{g} /$ day. In children aged 6-11 years, this is equivalent to $\leq 200,201-400$, and $>400 \mu \mathrm{g} /$ day. Screening for adrenal suppression is recommended in all children and adolescents receiving a high dose of ICS for 6 months or more; in children with symptoms suggestive of insufficient amount of cortisol regardless of ICS dosage and/or in patients with factors that increase the systemic corticosteroid exposure [37]. Children in our study received $560 \mu \mathrm{g} /$ day budesonide, equivalent to $280 \mu \mathrm{g} /$ day fluticasone, i.e., subject to the age, a lowto-medium dose. As such, our findings provide support for the referenced guidelines. However, we acknowledge that in addition to the validation efforts from Noppe et al. [19], an extensive comparison between HCC and alternative matrices would be required before any conclusive clinical recommendations based on HCC can be provided.

A strength of our study is that cortisol was measured over a prolonged period of time as we used scalp hair. Current non-stressed tests using serum, or saliva, represent an instantaneous secretion of cortisol and are sensitive to the variance in cortisol related to its pulsatile secretion and the circadian rhythm. HCC may be a robust way to study chronic suppression of cortisol production; however, one should note that no conclusions can be drawn on the HPA-axis acute stress response based on this metric. Another strength of our study is that we used a sensitive technique for the analysis, i.e., LCMS. Most studies on hair cortisol analyses employ ELISA, which, as mentioned before, performs poorly when measuring low cortisol concentrations. LCMS has a proven higher sensitivity in smaller hair sample volumes, making the method more suitable for studying lower cortisol levels. 
Our study has several limitations. We did not have information on ICS treatment adherence and the quality of the inhalation technique employed. Moreover, we did not have information on the exact duration of ICS therapy, other than ICS being used for at least 3 months. As a result, the effective amount of ICS that was deposited in the lungs was uncertain. This may be an explanation for the absence of a correlation between HCC and ICS dosage in our study. However, all asthmatic children visited the respiratory nurse specialist on a 3-monthly basis to ensure appropriate usage and performance, and the majority of children used metered dose inhalers and spacers. Finally, 3 out of 80 patients had a markedly high $\mathrm{HCC}(>7.5 \mathrm{pg} / \mathrm{mg})$. No clear differences in the measured characteristics of these patients compared to other cases were identified, and we have no clear explanation for these few outliers.

\section{Conclusion}

There was no evidence of suppression of basal cortisol production, as measured in scalp hair, in asthmatic children using ICS, compared to healthy controls.

Nonetheless, clinicians should be aware of a potential HPA-axis suppression in asthmatic patients during ICS therapy regardless of the dose prescribed. Further research is needed in asthmatic children with ICS therapy and a proven HPA-axis suppression to evaluate whether the measurement of cortisol in scalp hair is a useful tool for diagnosing adrenal insufficiency due to ICS in asthmatic children.

\section{Acknowledgments}

The authors would like to thank Ms. M.E. Bisschoff, research nurse, Erasmus MC, Rotterdam, The Netherlands, for her help in the recruitment of healthy children. We also thank the participat- ing primary and secondary schools and their students. We are grateful to Mirjam Vreugdenhil for her assistance in the preparation of the manuscript.

\section{Statement of Ethics}

This article does not contain any studies with animals performed by any of the author. All procedures performed in studies involving human participants were in accordance with the ethical standard of the institutional and/or national research committee and with the 1964 Helsinki Declaration and its later amendments or comparable ethical standards. Informed consent was obtained from all individual participants included in the study.

\section{Disclosure Statement}

The authors have no conflicts of interest to disclose.

\section{Author Contribution}

All authors approved the final manuscript as submitted and agree to be accountable for all aspects of work.

M.P.S. conceptualized and designed the study, drafted the initial manuscript, conducted analyses of the hair samples, analyzed and interpreted the data, and approved the final manuscript as submitted.

E.H.G.v.L. conceptualized and designed the study, approved the final manuscript as submitted, and had the general supervision of the study.

G.N. analyzed the hair samples, conceptualized and designed the study, analyzed and interpreted the data, and approved the final manuscript as submitted.

Y.B.d.R. conceptualized and designed the study, conducted analyses of the hair samples, and approved the final manuscript as submitted.

D.K.v.D. collected the data and approved the final manuscript as submitted.

E.L.T.v.d.A. conceptualized and designed the study, drafted the initial manuscript, analyzed and interpreted the data, approved the final manuscript as submitted, and had the general supervision of the study.

\section{References}

1 WHO: Asthma. Fact Sheet, World Health Organization, 2011.

2 Reddel HK, Bateman ED, Becker A, Boulet LP, Cruz AA, Drazen JM, Haahtela T, Hurd $\mathrm{SS}$, Inoue $\mathrm{H}$, de Jongste JC, Lemanske RF Jr, Levy ML, O’Byrne PM, Paggiaro P, Pedersen SE, Pizzichini E, Soto-Quiroz M, Szefler SJ, Wong GW, FitzGerald JM: A summary of the new GINA strategy: a roadmap to asthma control. Eur Respir J 2015;46:622-639.
3 Lipworth BJ: Systemic adverse effects of in haled corticosteroid therapy: a systematic review and meta-analysis. Arch Intern Med 1999;159:941-955.

4 Dahl R: Systemic side effects of inhaled corticosteroids in patients with asthma. Respir Med 2006;100:1307-1317.

5 Grossman A, Johannsson G, Quinkler M, Zelissen P: Therapy of endocrine disease: perspectives on the management of adrenal in sufficiency: clinical insights from across Europe. Eur J Endocrinol 2013;169:R165-R175. 
6 Todd GR, Acerini CL, Ross-Russell R, Zahra S, Warner JT, McCance D: Survey of adrenal crisis associated with inhaled corticosteroids in the United Kingdom. Arch Dis Child 2002; 87:457-461.

7 Edwards LD, Heyman AH, Swidan S: Hypocortisolism: an evidence-based review. Integr Med 2011;10:30.

8 Ahmet A, Kim H, Spier S: Adrenal suppression: a practical guide to the screening and management of this under-recognized complication of inhaled corticosteroid therapy. Allergy Asthma Clin Immunol 2011;7:13.

9 Patel L, Wales JK, Kibirige MS, Massarano AA, Couriel JM, Clayton PE: Symptomatic adrenal insufficiency during inhaled corticosteroid treatment. Arch Dis Child 2001; 85:330-334.

10 Zwaan CM, Odink RJ, Delemarre-van de Waal HA, Dankert-Roelse JE, Bokma JA: Acute adrenal insufficiency after discontinuation of inhaled corticosteroid therapy. Lancet (London, England) 1992;340:1289-1290.

11 Cavkaytar O, Vuralli D, Arik Yilmaz E, Buyuktiryaki B, Soyer O, Sahiner UM, Kandemir N, Sekerel BE: Evidence of hypothalamic-pituitary-adrenal axis suppression during moderate-to-high-dose inhaled corticosteroid use. Eur J Pediatr 2015;174:1421-1431.

12 Smith RW, Downey K, Gordon M, Hudak A, Meeder R, Barker S, Smith WG: Prevalence of hypothalamic-pituitary-adrenal axis suppression in children treated for asthma with inhaled corticosteroid. Paediatr Child Health 2012;17:e34-e39.

13 Zöllner EW, Lombard CJ, Galal U, Hough S, Irusen EM, Weinberg E: Screening for hypothalamic-pituitary-adrenal axis suppression in asthmatic children remains problematic: a cross-sectional study. BMJ Open 2013; 3:e002935.

14 Zöllner EW: Hypothalamic-pituitary-adrenal axis suppression in asthmatic children on inhaled corticosteroids (Part 2) - the risk as determined by gold standard adrenal function tests: a systematic review. Pediatr Allergy Immunol 2007;18:469-474.

15 Manenschijn L, Koper JW, Lamberts SW, van Rossum EF: Evaluation of a method to measure long term cortisol levels. Steroids 2011; 76:1032-1036.

16 Stalder T, Steudte S, Alexander N, Miller R, Gao W, Dettenborn L, Kirschbaum C: Cortisol in hair, body mass index and stress-related measures. Biol Psychol 2012;90:218-223.
17 D’Anna-Hernandez KL, Ross RG, Natvig CL, Laudenslager ML: Hair cortisol levels as a retrospective marker of hypothalamic-pituitary axis activity throughout pregnancy: comparison to salivary cortisol. Physiol Behav 2011; 104:348-353.

18 Sauve B, Koren G, Walsh G, Tokmakejian S, Van Uum SH: Measurement of cortisol in human hair as a biomarker of systemic exposure. Clin Invest Med 2007;30:E183-E191.

19 Noppe G, Van Rossum EF, Koper JW, Manenschijn L, Bruining GJ, de Rijke YB, van den Akker EL: Validation and reference ranges of hair cortisol measurement in healthy children. Horm Res Paediatr 2014;82:97-102.

20 Kamps AW, Molenmaker M, Kemperman R, van der Veen BS, Bocca G, Veeger NJ: Children with asthma have significantly lower long-term cortisol levels in their scalp hair than healthy children. Acta Paediatr 2014; 103:957-961.

21 Smy L, Shaw K, Smith A, Russell E, Van Uum S, Rieder M, Carleton B, Koren G: Hair cortisol as a novel biomarker of HPA suppression by inhaled corticosteroids in children. Pediatr Res 2015;78:44-47.

22 Mosteller R: Simplified calculation of bodysurface area. N Engl J Med 1987;317:1098.

23 Knol F, Boelhouwer J, Ross J: Statusontwikkeling van wijken in Nederland 1998-2010. Den Haag: Sociaal en Cultureel Planbureau; 2012.

24 Noppe G, de Rijke YB, Dorst K, van den Akker EL, van Rossum EF: LC-MS/MS-based method for long-term steroid profiling in human scalp hair. Clin Endocrinol (Oxf) 2015; 83:162-166.

25 Fredriks AM, van Buuren S, Burgmeijer RJ, Meulmeester JF, Beuker RJ, Brugman E, Roede MJ, Verloove-Vanhorick SP, Wit JM: Continuing positive secular growth change in The Netherlands 1955-1997. Pediatr Res 2000;47:316-323.

26 NVK: Asthma in children, 2013 (Dutch guidelines). https://www.nvk.nl/Portals/0/ richtlijnen/Astmakinderen/Richtlijn $\% 20$ astma\%20bij\%20kinderen\%20NVK\%20GEAUTORISEERD \%20DEFINITIEF\% 20 14102013.pdf.
27 Karlén J, Frostell A, Theodorsson E, Faresjö T, Ludvigsson J: Maternal influence on child HPA axis: a prospective study of cortisol levels in hair. Pediatrics 2013;132:e1333-e1340.

28 Bailey D, Colantonio D, Kyriakopoulou L, Cohen AH, Chan MK, Armbruster D, Adeli $\mathrm{K}$ : Marked biological variance in endocrine and biochemical markers in childhood: establishment of pediatric reference intervals using healthy community children from the CALIPER cohort. Clin Chem 2013;59:1393-1405.

29 Zöllner EW, Lombard CJ, Galal U, Hough FS, Irusen EM, Weinberg E: Hypothalamic-pituitary-adrenal axis suppression in asthmatic school children. Pediatrics 2012;130:e1512e1519.

30 Mahachoklertwattana P, Sudkronrayudh K, Direkwattanachai C, Choubtum L, Okascharoen C: Decreased cortisol response to insulin induced hypoglycaemia in asthmatics treated with inhaled fluticasone propionate. Arch Dis Child 2004;89:1055-1058.

31 Fitzgerald D, Van Asperen P, Mellis C, Honner M, Smith L, Ambler G: Fluticasone propionate $750 \mu \mathrm{g} / \mathrm{day}$ versus beclomethasone dipropionate $1,500 \mu \mathrm{g} /$ day: comparison of efficacy and adrenal function in paediatric asthma. Thorax 1998;53:656-661.

32 Heller MK, Laks J, Kovesi TA, Ahmet A: Reversal of adrenal suppression with ciclesonide. J Asthma 2010;47:337-339.

33 Ribeiro LB: Budesonide: safety and efficacy aspects of its long-term use in children. Pediatr Allergy Immunol 1993;4:73-78.

34 Muley P, Shah M, Muley A: Safety of inhaled fluticasone propionate therapy for pediatric asthma - a systematic review. Curr Drug Saf 2013;8:186-194.

35 Nagakura T, Tanaka T, Arita M, Nishikawa K, Shigeta M, Wada N, Matsumoto T, Hiraba K, Fukuda N: Salivary cortisol monitoring: determination of reference values in healthy children and application in asthmatic children. Allergy Asthma Proc 2012;33:362-369.

36 Bacharier LB, Raissy HH, Wilson L, McWilliams B, Strunk RC, Kelly HW: Long-term effect of budesonide on hypothalamic-pituitary-adrenal axis function in children with mild to moderate asthma. Pediatrics 2004; 113:1693-1699.

37 Issa-El-Khoury K, Kim H, Chan ES, Vander Leek T, Noya F: CSACI position statement: systemic effect of inhaled corticosteroids on adrenal suppression in the management of pediatric asthma. Allergy Asthma Clin Immunol 2015;11:9. 